\title{
Serum free testosterone, leptin and soluble leptin receptor changes in a 6-week strength-training programme
}

\author{
I. Ara, J. Perez-Gomez, G. Vicente-Rodriguez, J. Chavarren, C. Dorado and J. A. L. Calbet* \\ Department of Physical Education, University of Las Palmas de Gran Canaria, Spain
}

(Received 6 March 2006 - Revised 10 July 2006 - Accepted 19 July 2006)

Strength training is usually associated with a reduction in fat mass and with muscle hypertrophy. The aim of the present study was to examine whether the serum free leptin index (FLI), measured by the molar excess of soluble leptin receptor (sOB-R) over leptin, is increased by 6 weeks of strength training. Eighteen male, physical education students were randomly assigned to two groups: a strength-training ( $n$ 12) and a control group $(n 6)$. Body composition (lean body mass and body fat) determined by dual-energy X-ray absorptiometry (DXA), muscle performance and leptin, sOB-R, total testosterone and free testosterone concentrations were determined before and after training. Fat mass was reduced by $1 \mathrm{~kg}$ with strength training $(P<0 \cdot 05)$. Lean body mass of trained extremities was increased by $3 \%(P<0 \cdot 05)$, while the concentration of free testosterone in serum was reduced by $17 \%(P<0.05)$ after training. However, despite the reduction in fat mass and free testosterone, serum leptin concentration was not significantly affected by strength training, even after accounting for the differences in body fat. By contrast, for a given fat mass, the sOB-R was increased by $13 \%(P<0.05)$ at the end of the strength-training programme, although the molar excess of sOB-R over leptin remained unchanged. Therefore, the quantity of free leptin available to bind to the target tissues was not significantly affected by the short strengthtraining programme, which elicited a $7 \%$ reduction in fat mass.

Free leptin index: Obesity: Weight loss: Exercise

Leptin is a hormone released by the adipose tissue that assists in the regulation of body weight and energy homeostasis (Pelleymounter et al. 1995). Plasma leptin concentration is directly proportional to adipose tissue mass and acts on the hypothalamus as a signal of the amount of energy stored as fat (Considine et al. 1996; Friedman \& Halaas, 1998). Increasing fat mass results in higher leptin levels, which induce satiety (Mars et al. 2006) and a mild enhancement of basal energy expenditure (Considine et al. 1996). Conversely, reducing the body fat stores through regular exercise and/or dieting results in a proportional reduction of circulating leptin (Perusse et al. 1997; Houmard et al. 2000; Thong et al. 2000), although exercise can also elicit changes in leptin concentration without an accompanying change in body composition (van Aggel-Leijssen et al. 1999).

A circulating soluble form of the leptin receptor, soluble leptin receptor (sOB-R), is the main leptin-binding protein that determines the free fraction of the circulating hormone, presumably the biologically active form of leptin (Lammert et al. 2001; Chan et al. 2002; Stein et al. 2006). sOB-R facilitates the transport of leptin from its peripheral site of production to the target tissues (Tartaglia, 1997; Maamra et al. 2001). The plasma sOB-R concentration increases with weight loss (van Dielen et al. 2002; Stein et al. 2006). Thus, the concentration of free leptin may be reduced even more than the concentration of total leptin with weight loss.
In children with protein energy malnutrition (PEM), the molar excess of sOB-R over leptin was about seventy times higher than in normal children (Stein et al. 2006). Two weeks after refeeding, the plasma leptin concentration was found to have increased by $31 \%$ over the control group while the sOB-R was reduced by about $45 \%$ in the PEM children, even though both weight and BMI mean values were still below those in the control group (Stein et al. 2006). An excess of sOB-R inhibits the bioactivity of leptin through its competition with the membrane receptor (Zastrow et al. 2003) and may reduce the availability of free leptin for transport to the cerebrospinal fluid (Landt et al. 2000).

Regular physical activity (i.e. exercise training) is associated with increased energy demand and changes in body composition that in turn could influence plasma leptin concentration (Landt et al. 1997; Leal-Cerro et al. 1998; van Aggel-Leijssen et al. 1999; Reseland et al. 2001; Zaccaria et al. 2002). It remains unknown, however, to what extent exercise training affects the plasma concentration of sOB-R and the balance between leptin and its soluble receptor.

Strength training increases muscle mass, strength and power while fat mass is reduced (Hakkinen, 1989; McCall et al. 1996). In the short term, a strength-training session elicits a transient increase in basal plasma testosterone concentration in young men (Hakkinen et al. 1998; Kraemer et al. 1998). In the long term, strength training has also been associated

Abbreviations: DXA, dual-energy X-ray absorptiometry; FLI, free leptin index; PEM, protein energy malnutrition; 1RM, one-repetition maximum; sOB-R, soluble leptin receptor; WB, whole body; WHR, waist-to-hip ratio.

* Corresponding author: Jose A. L. Calbet, fax +34 928 458867, email lopezcalbet@terra.es 
with a small increase $(8 \%)$ in basal serum total testosterone concentration (Gorostiaga et al. 2004), although the free fraction seems not to be affected (Ahtiainen et al. 2003; Gorostiaga et al. 2004). However, intensive strength training may be associated with a reduction in serum testosterone (Raastad et al. 2001), and this effect may be accentuated by energy deprivation (Bergendahl et al. 1998). Free plasma testosterone has been reported to be inversely related to sOB-R (Chan et al. 2002) and leptin (Luukkaa et al. 1998). Moreover, the weekly administration of $200 \mathrm{mg}$ testosterone enanthate over 12 months has been associated with a $44 \%$ decrease in mean serum leptin concentration (Luukkaa et al. 1998), probably due to the suppressive effect of testosterone on leptin production (Wabitsch et al. 1997). Thus, strength training may cause changes in the relationship between fat mass and the plasma levels of leptin, sOB-R and the molar excess of sOB-R over leptin, an estimation of the free leptin index (FLI; Misra et al. 2004; Stein et al. 2006), which may be modulated in part by alterations in the androgenic status.

The aims of the present study were therefore: (1) to determine whether a 6-week strength-training programme has an effect on circulating levels of leptin, sOB-R, the FLI and testosterone; (2) to determine to what extent strength traininginduced changes in body composition are associated with changes in serum plasma concentrations of leptin, its soluble receptor, and free leptin; (3) to determine whether changes in total or free testosterone influence the response of leptin, sOB-R, and the FLI to strength training.

\section{Methods}

\section{Subjects}

Eighteen healthy men (age 23 (SD 2) years, height 173 (SD 5) $\mathrm{cm}$, body mass 73 (SD 6) $\mathrm{kg}$, body fat 17 (SD 6) \%) participated in this investigation. Written informed consent was obtained from all subjects after they had received a full explanation of the study procedures. The subjects were randomly assigned to two groups: one performed a strength-training (ST, $n$ 12) programme and the other was a control group (CON, $n$ 6). Their physical characteristics are presented in Table 1. All of the subjects were healthy and physically active and were familiar with strength training. In addition, they all answered a questionnaire providing information about personal data, sports participation (including the number of training hours per week) and medical history (including past injuries and medication). The study was performed in accordance with the Helsinki Declaration of 1975, and was approved by the Ethical Committee of the University of Las Palmas de Gran Canaria.

Table 1. Characteristics of subjects at the beginning of the study (Mean values with their standard errors)

\begin{tabular}{lrrrrr}
\hline & \multicolumn{2}{c}{ Strength group } & & \multicolumn{2}{c}{ Control group } \\
\cline { 2 - 3 } & Mean & SEM & & Mean & SEM \\
\hline Age (years) & 22.7 & 0.6 & & 23.7 & 0.7 \\
Body mass (kg) & 74.7 & 2.2 & & 70.3 & 1.8 \\
Height (cm) & 173.9 & 2.2 & & 171.9 & 1.9 \\
\hline
\end{tabular}

Study design

Each subject performed two test sessions, one before and one after strength training. In both test sessions body composition was determined by dual-energy X-ray absorptiometry (DXA) and by the maximum weight that could be lifted at least once for each exercise (one-repetition maximum, 1RM) used during the training period. Before testing and training, subjects were familiarized with the experimental procedures. The total duration of the study was 8 weeks. Baseline testing was completed during the first week. This was followed by a 6-week period of supervised experimental strength training (Table 2). Resting blood samples were drawn at baseline and at the end of the study, $48-72 \mathrm{~h}$ after the last training session. Venous blood samples were taken between 07.00 and 08.00 hours, after $12 \mathrm{~h}$ overnight fasting. The blood samples were allowed to clot at $4^{\circ} \mathrm{C}$ and then centrifuged at the same temperature (Allegra 21R, Beckman Instruments Inc, Fullerton, CA, USA). The serum obtained was separated and frozen at $-80^{\circ} \mathrm{C}$ for later analysis.

\section{Anthropometry and body composition}

Anthropometric measurements were obtained on each subject. Height was measured in the upright position to the nearest millimetre (Atlántida, Añó Sayol, Barcelona, Spain). Body mass was determined using a balance with a $50 \mathrm{~g}$ imprecision (Atlántida), calibrated with M1 calibration masses (tolerance $<0.005 \%$ in mass).

Total and regional body composition was assessed by DXA (Hologic QDR-1500, Hologic Corp., software version 7.10, Waltham, MA, USA) as described elsewhere (Calbet et al. 1998; Ara et al. 2004, 2006). Lean body mass (g) and body fat were calculated from whole-body scans. Whole-body scans were submitted to a regional analysis to determine the composition of the arm, leg and trunk regions. The arm region included

Table 2. Strength-training programme (sets $\times$ repetitions). Percentage of 1RM 000 (the maximum weight that could be lifted at least once for each excercise) lifted during training is given in parentheses. A 90-s rest period was given between exercise sets

\begin{tabular}{lll}
\hline Week & Session & \multicolumn{1}{c}{ Weight lifted per session } \\
\hline 1 & 1 & $10(50 \%)+6(70 \%)+3(90 \%)$ \\
& 2 & $10(50 \%)+6(70 \%)+3(90 \%)$ \\
& 3 & $10(50 \%)+6(70 \%)+3(90 \%)$ \\
2 & 4 & $2 \times 10(50 \%)+2 \times 6(70 \%)+2 \times 3(90 \%)$ \\
& 5 & $10(50 \%)+6(70 \%)+3(90 \%)$ \\
3 & 6 & $2 \times 10(50 \%)+6(70 \%)+3(90 \%)$ \\
& 7 & $2 \times 10(50 \%)+2 \times 6(70 \%)+2 \times 3(90 \%)$ \\
4 & 8 & $2 \times 10(50 \%)+2 \times 6(70 \%)+2 \times 3(90 \%)$ \\
& 10 & $2 \times 10(50 \%)+2 \times 6(70 \%)+2 \times 3(90 \%)$ \\
& 11 & $2 \times 10(50 \%)+2 \times 6(70 \%)+2 \times 3(90 \%)$ \\
5 & 12 & $3 \times 10(50 \%)+3 \times 6(70 \%)+3 \times 3(90 \%)$ \\
& 13 & $2 \times 10(50 \%)+2 \times 6(70 \%)+2 \times 3(90 \%)$ \\
& 14 & $2 \times 10(50 \%)+2 \times 6(70 \%)+2 \times 3(90 \%)$ \\
& 15 & $3 \times 10(50 \%)+3 \times 6(70 \%)+3 \times 3(90 \%)$ \\
& 17 & $3 \times 10(50 \%)+3 \times 6(70 \%)+3 \times 3(90 \%)$ \\
& 16 & $3 \times 10(50 \%)+3 \times 6(70 \%)+3 \times 3(90 \%)$ \\
& &
\end{tabular}


the hand, forearm and arm, and was separated from the trunk by an inclined line crossing the scapulo-humeral joint, such that the humeral head was located in the arm region. The leg region included the foot, the lower leg and the upper leg, and was separated from the trunk by an inclined line passing just below the pelvis, which bisected the femoral neck crossing the neck of the femur. The trunk region included the rest of the body minus the arm, leg and head regions. The head region comprised all skeletal parts of the skull and cervical vertebra above a horizontal line passing just below the jawbone. With this analysis, regional body fat and lean mass can be assessed with a coefficient of variation below $5 \%$ (Calbet et al. 1998). Lean mass of the upper and lower extremities was assumed to be equivalent to the muscle mass of the upper and lower extremities (Shih et al. 2000; Kim et al. 2002).

\section{Strength assessment and strength-training programmes}

Maximum strength (1RM) for all exercises used during training (parallel squat, leg extension, inclined leg press, leg curl and hip flexors) was assessed immediately before and at the end of the strength-training period. These exercises were performed on weight-lifting equipment (Technogym Ltd, Barcelona, Spain). The parallel squat and the inclined leg press were performed with a range of motion between full extension and a knee angle of $90^{\circ}$. All the available range of motion was used during the leg extension and leg curl exercises. The hip flexors exercise was carried out from the standing position by flexing the knee of one of the extremities, trying to bring it into contact with the chest while a pulley was attached at the ankle. Both limbs were trained alternatively. The 1RM values obtained were subsequently used to calculate the relative loads for the training protocols. The relative loads for each exercise ranged between $50 \%$ and $90 \%$ of the 1RM load (Table 2). Subjects completed a total of 414 sets (parallel squats: 102 sets, leg extension: 102 sets, inclined leg press: 102 sets, leg flexors: 54 sets, hip flexors: 54 sets). A 90$\mathrm{s}$ rest period was taken between exercise sets. All subjects completed the training programme. The energy expenditure during the strength-training sessions was estimated according to the formula of McArdle et al. (1991), energy expenditure $(\mathrm{kJ})=(0 \cdot 36) \times($ body mass in $\mathrm{kg}) \times($ duration of exercise in minutes), and ranged between 1047 and $1424 \mathrm{~kJ}$ per session.

\section{Leptin, soluble leptin receptor and testosterone assays}

Serum leptin, sOB-R and total and free testosterone were determined by ELISA (ELx800 Universal Microplate Reader, Bioteck Instruments Inc., VT, USA). Serum leptin, sOB-R and free testosterone were measured by using reagent kits from Diagnostic Systems Laboratories (Webster, TX, USA), and total testosterone with reagent kits from Diagnostics Biochemical Canada (London, ON, Canada). The sensitivity of the total leptin and sOB-R assays was 0.05 and $0.2 \mathrm{ng} / \mathrm{ml}$, respectively. The intra-assay $\mathrm{CVs}$ were $3.8 \%$ and $4.1 \%$ and the interassay CVs were $4.4 \%$ and $4.9 \%$ for leptin and sOB-R, respectively. For the total and free testosterone assays, the sensitivity was $1.74 \mathrm{nmol} / 1$ and $0.66 \mathrm{pmol} / \mathrm{l}$, respectively, and the intra- and inter-assay $\mathrm{CVs}$ were $10.8 \%$ and $11.4 \%$ for total testosterone and $6.5 \%$ and $3.1 \%$ for free testosterone, respectively. The FLI, the molar excess of
sOB-R over leptin, was calculated as sOB-R divided by leptin multiplied by $0 \cdot 13$ (Stein et al. 2006).

\section{Statistical analyses}

The statistical analyses was performed using the Statistical Package for the Social Sciences version 11.0 (SPSS Inc., Chicago, IL, USA). All data are reported as means with their standard errors. The effect of strength training on the dependent variables was assessed using ANOVA for repeated measures. The Mauchly's test of sphericity was run before the ANOVA and in case of violation of the sphericity assumption, the degrees of freedom were adjusted according to the HuynhFeldt test. Pairwise comparisons were carried out with Tukey's test. To determine whether changes in fat mass accounts for the effects observed in leptin, sOB-R and the FRI, ANCOVA was run using the changes in total fat mass as a covariant. Pearson's correlation coefficients were used to assess associations between leptin, sOB-R, the FLI, testosterone and body composition changes. A statistical test was considered significant at the $P \leq 0.05$ level (two-tailed).

\section{Results}

Body composition

Total body mass was not significantly modified either in the control or in the strength-training group (Table 3 ). The strength training resulted in a $3.1 \%$ increase in the muscle mass of trained muscles $(P<0 \cdot 05)$. Total fat mass decreased by $7 \%(P<0.05)$ and the fat mass in the trunk, lower and upper extremities was reduced by 8,7 and $13 \%$, respectively (all $P<0.05$ ), following strength training. Consequently, at the end of the study, the percentage of body fat was 1.3 units lower in the strength-training group $(P<0.05)$. Likewise, the percentage of body fat in the trunk, lower and upper extremities was significantly reduced following strength training.

\section{Maximal strength}

The strength-training group significantly improved 1RM values in all exercises [inclined leg press (13\%), squats $(27 \%)$ leg extension (16\%), leg flexion (12\%) and hip flexors (29\%)] compared with initial 1RM values (all $P<0 \cdot 05$; Fig. 1 ).

\section{Leptin, sOB-R, the FLI and testosterone changes}

Strength training did not significantly alter the basal concentrations of serum leptin, sOB-R, and the FLI or mean total testosterone levels (Table 4). Free testosterone concentration was reduced by $17 \%$ in the strength-training group $(P<0.05)$. However, for a given fat mass, sOB-R was increased by $13 \%(P<0 \cdot 05)$.

There was no relationship between the changes in leptin, sOB-R, the FLI, total and free testosterone, on the one hand, and the changes in body composition on the other. However, the change in leptin correlated with the change in sOB-R concentration $(r-0 \cdot 50, P<0 \cdot 05)$. The change in sOB-R concentration correlated inversely with the changes in total testosterone $(r-0.56, P<0 \cdot 05)$. 
Table 3. Total and regional soft-tissue composition before and after the resistance-training period in all groups

(Mean values with their standard errors)

\begin{tabular}{|c|c|c|c|c|c|c|c|c|}
\hline & \multicolumn{4}{|c|}{ Strength group } & \multicolumn{4}{|c|}{ Control group } \\
\hline & \multicolumn{2}{|c|}{ Before } & \multicolumn{2}{|c|}{ After } & \multicolumn{2}{|c|}{ Before } & \multicolumn{2}{|c|}{ After } \\
\hline & Mean & SEM & Mean & SEM & Mean & SEM & Mean & SEM \\
\hline \multicolumn{9}{|l|}{ Lean mass (kg) } \\
\hline Whole body & 55.9 & $1 \cdot 2$ & $56 \cdot 5$ & $1 \cdot 2$ & $56 \cdot 8$ & $2 \cdot 3$ & 55.9 & $2 \cdot 9$ \\
\hline Trunk & $26 \cdot 8$ & 0.7 & $27 \cdot 0$ & 0.7 & $27 \cdot 6$ & 0.8 & $27 \cdot 0$ & $1 \cdot 0$ \\
\hline Lower extremity & 9.5 & 0.2 & $9 \cdot 8$ & $0.2^{*}$ & $9 \cdot 4$ & 0.6 & 9.2 & 0.5 \\
\hline Upper extremity & $3 \cdot 1$ & $0 \cdot 1$ & $3 \cdot 1$ & 0.1 & $3 \cdot 3$ & 0.3 & $3 \cdot 2$ & 0.4 \\
\hline \multicolumn{9}{|l|}{ Fat mass $(\mathrm{kg})$} \\
\hline Whole body & $14 \cdot 2$ & $1 \cdot 6$ & $13 \cdot 2$ & $1 \cdot 6^{*}$ & 9.51 & $2 \cdot 88$ & $10 \cdot 12$ & 2.73 \\
\hline Trunk & $6 \cdot 0$ & 0.9 & 5.5 & $0.9^{*}$ & 3.57 & 1.14 & 3.93 & 0.94 \\
\hline Lower extremity & $2 \cdot 9$ & 0.3 & $2 \cdot 7$ & $0.3^{*}$ & 2.07 & 0.84 & $2 \cdot 13$ & 0.84 \\
\hline Upper extremity & 0.8 & 0.0 & 0.7 & $0.0^{*}$ & 0.50 & 0.14 & 0.54 & 0.12 \\
\hline \multicolumn{9}{|l|}{ Percentage of fat (\%) } \\
\hline Whole body & $19 \cdot 1$ & $1 \cdot 8$ & $17 \cdot 8$ & $1.8^{*}$ & $13 \cdot 6$ & $3 \cdot 6$ & 14.5 & $3 \cdot 1$ \\
\hline Trunk & $17 \cdot 3$ & $2 \cdot 2$ & $16 \cdot 0$ & $2 \cdot 2^{*}$ & $11 \cdot 1$ & 1.4 & $12 \cdot 3$ & $1 \cdot 0$ \\
\hline Lower extremity & $22 \cdot 0$ & $1 \cdot 8$ & $20 \cdot 4$ & $1.8^{*}$ & $16 \cdot 8$ & $2 \cdot 4$ & $17 \cdot 4$ & $2 \cdot 3$ \\
\hline Upper extremity & 18.5 & 1.5 & $17 \cdot 6$ & $1.6^{*}$ & $12 \cdot 4$ & 0.9 & $13 \cdot 7$ & 0.5 \\
\hline
\end{tabular}

${ }^{*} P<0.05$ compared to pre-training values.

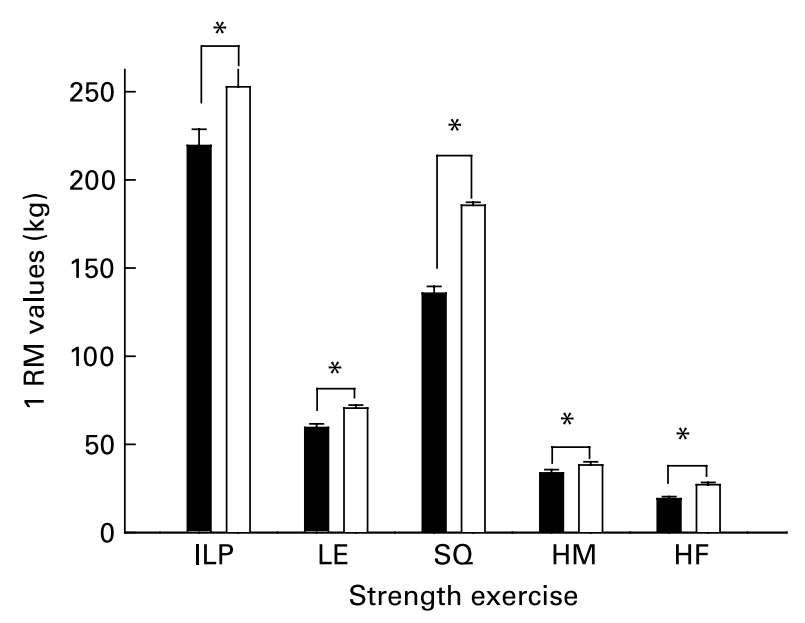

Fig. 1. Effects of strength training. ILP, inclined leg press; LE, leg extension; $\mathrm{SQ}$, parallel squat; $\mathrm{HM}$, leg curl (hamstrings) $\mathrm{HF}$, hip flexors; $1 \mathrm{RM}$, one-repetition maximum. $\square$, Before training; $\square$, after training. ${ }^{\star} P<0.05 \mathrm{com}$ pared to pre-training values
When all subjects were pooled together, a close relationship was observed between leptin concentrations (Table 5) and the molar excess of sOB-R over leptin (Fig. 2) with fat mass and the waist circumference. However, no relationship was observed between the sOB-R and fat mass before training. At the end of the follow-up, sOB-R was inversely related to the hip circumference $(r-0.59, P<0.05)$ and a trend for a negative correlation was also observed with the waist circumference $(r-0 \cdot 48, P=0 \cdot 07)$.

\section{Discussion}

Although 6 weeks of strength training resulted in a significant reduction in fat mass, an improvement in dynamic muscle strength and an increase in lean body mass of the trained extremities, the present investigation shows that strength training is not associated with significant changes in basal concentration in serum of leptin, sOB-R or the molar excess of sOB-R over leptin (as an estimation of the FLI). Even after adjusting the hormonal response for changes in whole-body fat mass, no effect of strength training was observed.

Table 4. Leptin, soluble leptin receptor (sOB-R), molar excess of sOB-R over leptin and total and free testosterone values in both groups before and after training

(Mean values with their standard errors)

\begin{tabular}{|c|c|c|c|c|c|c|c|c|}
\hline & \multicolumn{4}{|c|}{ Strength-training group } & \multicolumn{4}{|c|}{ Control group } \\
\hline & \multicolumn{2}{|c|}{ Before } & \multicolumn{2}{|c|}{ After } & \multicolumn{2}{|c|}{ Before } & \multicolumn{2}{|c|}{ After } \\
\hline & Mean & SEM & Mean & SEM & Mean & SEM & Mean & SEM \\
\hline Leptin (ng/ml) & $5 \cdot 9$ & $1 \cdot 3$ & $5 \cdot 4$ & $1 \cdot 1$ & 3.5 & 0.4 & $4 \cdot 3$ & 0.6 \\
\hline $\mathrm{sOB}-\mathrm{R}(\mathrm{ng} / \mathrm{ml})$ & $9 \cdot 1$ & 0.3 & $9 \cdot 4$ & 0.4 & $10 \cdot 4$ & $1 \cdot 2$ & $9 \cdot 8$ & 0.5 \\
\hline Molar excess of sOB-R over leptin & 0.30 & 0.06 & 0.30 & 0.05 & 0.41 & 0.04 & 0.32 & 0.04 \\
\hline Total testosterone $(\mathrm{nmol} / \mathrm{l})$ & $29 \cdot 8$ & $3 \cdot 8$ & $16 \cdot 3$ & $1 \cdot 0^{*}$ & 35.4 & $7 \cdot 3$ & $27 \cdot 8$ & $9 \cdot 7$ \\
\hline Free testosterone (pmol/l) & $56 \cdot 2$ & $5 \cdot 9$ & 44.4 & $4 \cdot 5^{\star}$ & $67 \cdot 0$ & $6 \cdot 6$ & 62.5 & $6 \cdot 9$ \\
\hline
\end{tabular}

${ }^{*} P<0.05$ compared to pre-training values. 

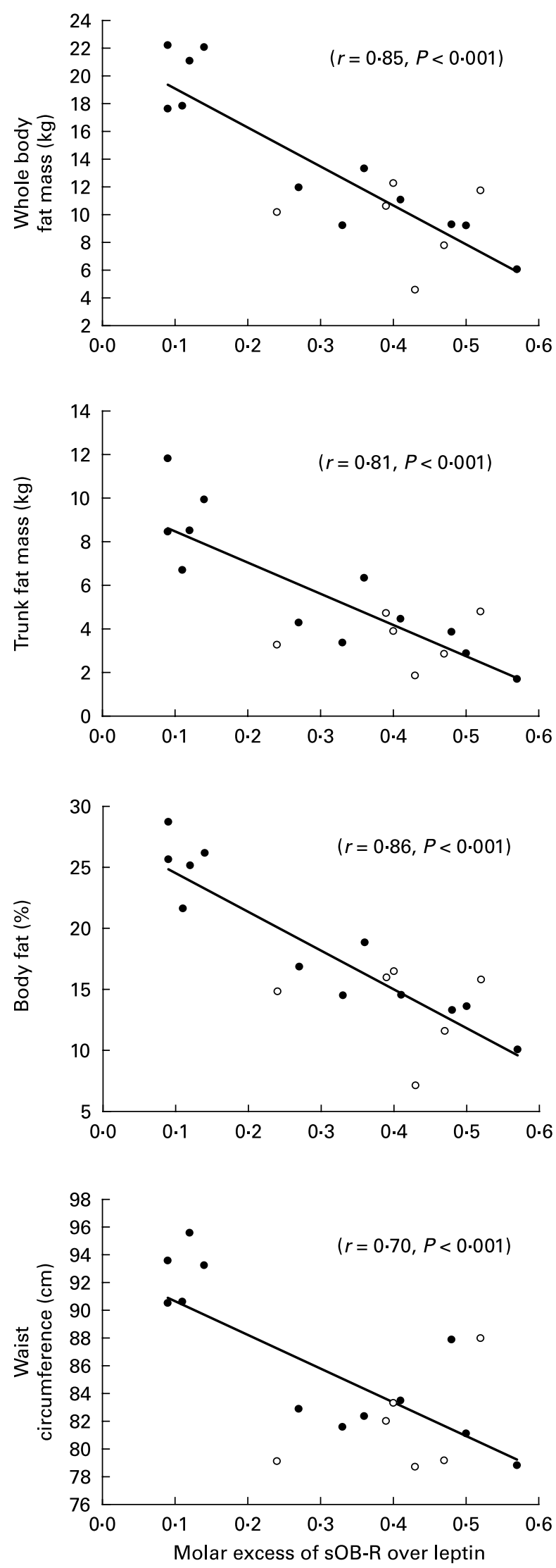

Fig. 2. Relationship between the molar excess of soluble leptin receptor (sOB-R) over leptin and adiposity.
Lean mass increases of around $3 \%$ have been reported following a 6-month whole-body strength-training programme in young people (Lemmer et al. 2001; Ryan et al. 2004). However, in the present study the effect at the whole-body level was smaller, probably because only the muscles of the lower extremities were trained. However, the lean mass of the lower extremities was increased by $3 \%$, showing that despite being of shorter duration than other studies (Lemmer et al. 2001; Ryan et al. 2004), our strength-training programme was efficient, in agreement with previous studies, as reviewed by Nissen \& Sharp (2003).

In accordance with the present results, Kanaley et al. (2001) did not observe any change in basal serum leptin concentration following 6 weeks of strength training in middle-aged men. However, in contrast to the present investigation, no reduction in body fat mass or increase in muscle mass was observed with strength training in the study by Kanaley et al. (2001). Sixteen weeks of strength training resulted in lower basal serum leptin levels in obese postmenopausal women who lost body fat, while leptin was not altered in the group of women without changes in their body fat mass during the training period (Ryan et al. 2000). The authors suggested that the change in basal serum leptin concentration was mediated by the loss of body fat.

The changes observed in whole-body composition with strength training in the present investigation clearly show that our subjects were in negative energy balance. The energy deficit (at least $37680 \mathrm{~kJ}$, or about $834 \mathrm{~kJ} / \mathrm{day}$, assuming no changes in the overall efficiency of the energy metabolism during this period) was covered by the oxidation of part of the fat deposits, as reflected by a $7 \%$ reduction in fat mass. Despite this decrease in fat mass, basal serum leptin concentration was not altered. This could be interpreted as meaning that our subjects developed a state of relatively elevated basal serum leptin concentration by comparison to the fat mass that they had before the start of the training programme. However, we can rule out this possibility because after accounting for the changes in fat mass, no significant effects were observed in leptin concentration. We also explored the possibility of an increase in the concentration of the bioavailable form of leptin, which may change independently of the total serum leptin concentration (Misra et al. 2004; Stein et al. 2006). An inverse relationship was in fact observed in the present investigation between serum sOB-R and some indexes of adiposity, as reported previously (Sandhofer et al. 2003). A high serum concentration of sOB-R, combined with reduced leptin and leptin/sOB-R index, has been reported in anorexic girls (Misra et al. 2004). Body weight gain resulted in a reduction in sOB-R and an increase in leptin and leptin/sOB-R index in the anorexic girls (Misra et al. 2004). In agreement, sOB-R increases with weight loss, probably due to the reduction in fat mass (Laimer et al. 2002; van Dielen et al. 2002). An inverse relationship between leptin and sOB-R changes has been reported (Chan et al. 2002; Gavrila et al. 2003) and confirmed in the present investigation. Thus, sOB-R is somewhat sensitive to changes in body composition (Chan et al. 2002; Reinehr et al. 2005; Stein et al. 2006). However, despite a $7 \%$ reduction in whole-body fat mass with strength training, no significant effects were observed in sOB-R in the present investigation. However, a $13 \%$ increase in SOB-R concentration adjusted for the wholebody fat mass was observed with strength training, meaning that for a given amount of fat mass, sOB-R is increased after strength training. An increase in sOB-R could decrease 
Table 5. Relationship between leptin, sOB-R, testosterone and fat mass

\begin{tabular}{lccccc}
\hline & $\begin{array}{c}\text { WB fat mass } \\
(\mathrm{kg})\end{array}$ & $\begin{array}{c}\text { Trunk fat mass } \\
(\mathrm{kg})\end{array}$ & $\begin{array}{c}\text { Waist circumference } \\
(\mathrm{cm})\end{array}$ & WHR body fat \\
\hline Leptin $(\mathrm{ng} / \mathrm{ml})$ & $0.89^{*}$ & $0.89^{*}$ & $0.91^{*}$ & $0.81^{*}$ & $0.54^{*}$ \\
sOB-R $(\mathrm{ng} / \mathrm{ml})$ & -0.11 & -0.12 & -0.12 & 0.02 & 0.22 \\
Total testosterone $(\mathrm{nmol} / \mathrm{l})$ & -0.13 & -0.08 & -0.10 & -0.07 & 0.01 \\
Free testosterone $(\mathrm{pmol} / \mathrm{l})$ & -0.04 & -0.08 & -0.05 & -0.06 & 0.00 \\
\hline
\end{tabular}

WB, whole body; sOB-R, leptin soluble receptor; WHR, waist-to-hip ratio.

${ }^{*} P<0.05$.

the quantity of free leptin available to interact with the target tissues, and with adipose tissue in particular. However, as the molar excess of sOB-R over leptin remained unchanged with strength training, such a possibility seems unlikely (Yang et al. 2004).

In vitro studies indicate that gonadal hormones, such as testosterone, may be important regulators of leptin secretion (Luukkaa et al. 1998). Androgens are reported to block adipogenesis (Lea-Currie et al. 1998). This endocrine regulation is supported by the presence of specific sex steroid receptors in fat tissue (Wade \& Gray, 1978; Dieudonne et al. 1998), indicating that adipocytes are targets for testosterone (RebuffeScrive et al. 1985). Although not all published studies have found a significant relationship between serum testosterone and leptin, a strong inverse association has been reported (Behre et al. 1997; Bhasin et al. 1997; Luukkaa et al. 1998). It has also been shown that 6 months of treatment with testosterone injections reduces fat mass by $16 \%$ (Young et al. 1993), probably because of a direct effect of testosterone at the level of adipocytes (Wabitsch et al. 1997). However, the mechanism underlying testosterone influences in leptin secretion remains to be elucidated. In the whole group, the decrease in testosterone concentration was inversely correlated with the changes in sOB-R. In agreement, free plasma testosterone has been reported to be inversely associated with sOB-R (Chan et al. 2002).

In summary, an intervention consisting of 6 weeks of strength training associated with a $1 \mathrm{~kg}$ reduction in fat mass and increases in lean body mass of the trained extremities did not result in significant changes in serum leptin concentration, even after accounting for the differences in body fat. By contrast, for a given fat mass, the sOB-R was increased at the end of the strength-training programme, although the molar excess of sOB-R over leptin (a measure of the FLI) remained unchanged. Thus, the present study indicates that the quantity of free leptin available to bind to the target tissues was not significantly affected by a short strength-training programme, which elicited a $7 \%$ reduction in fat mass.

\section{Acknowledgements}

We thank José Navarro de Tuero for excellent technical assistance. Funding was provided by the Ministerio de Ciencia y Tecnología (BFI2003-09638) and by the Dirección General de Universidades del Gobierno de Canarias (PI0422005/177).

\section{References}

Ahtiainen JP, Pakarinen A, Alen M, Kraemer WJ \& Hakkinen K (2003) Muscle hypertrophy, hormonal adaptations and strength development during strength training in strength-trained and untrained men. Eur J Appl Physiol 89, 555-563.

Ara I, Vicente-Rodriguez G, Jimenez-Ramirez J, Dorado C, SerranoSanchez JA \& Calbet JA (2004) Regular participation in sports is associated with enhanced physical fitness and lower fat mass in prepubertal boys. Int J Obes Relat Metab Disord 28, 1585-1593.

Ara I, Vicente-Rodriguez G, Perez-Gomez J, Jimenez-Ramirez J, Serrano-Sanchez JA, Dorado C \& Calbet JA (2006) Influence of extracurricular sport activities on body composition and physical fitness in boys: a 3-year longitudinal study. Int J Obes (Lond) 30, $1062-1071$.

Behre HM, Simoni M \& Nieschlag E (1997) Strong association between serum levels of leptin and testosterone in men. Clin Endocrinol (Oxf) 47, 237-240.

Bergendahl M, Aloi JA, Iranmanesh A, Mulligan TM \& Veldhuis JD (1998) Fasting suppresses pulsatile luteinizing hormone (LH) secretion and enhances orderliness of LH release in young but not older men. J Clin Endocrinol Metab 83, 1967-1975.

Bhasin S, Storer TW, Berman N, Yarasheski KE, Clevenger B, Phillips J, Lee WP, Bunnell TJ \& Casaburi R (1997) Testosterone replacement increases fat-free mass and muscle size in hypogonadal men. J Clin Endocrinol Metab 82, 407-413.

Calbet JA, Moysi JS, Dorado C \& Rodriguez LP (1998) Bone mineral content and density in professional tennis players. Calcif Tissue Int 62, 491-496.

Chan JL, Bluher S, Yiannakouris N, Suchard MA, Kratzsch J \& Mantzoros CS (2002) Regulation of circulating soluble leptin receptor levels by gender, adiposity, sex steroids, and leptin: observational and interventional studies in humans. Diabetes 51, 2105-2112.

Considine RV, Sinha MK, Heiman ML, et al. (1996) Serum immunoreactive-leptin concentrations in normal-weight and obese humans. N Engl J Med 334, 292-295.

Dieudonne MN, Pecquery R, Boumediene A, Leneveu MC \& Giudicelli Y (1998) Androgen receptors in human preadipocytes and adipocytes: regional specificities and regulation by sex steroids. Am J Physiol 274, C1645-C1652.

Friedman JM \& Halaas JL (1998) Leptin and the regulation of body weight in mammals. Nature 395, 763-770.

Gavrila A, Peng CK, Chan JL, Mietus JE, Goldberger AL \& Mantzoros CS (2003) Diurnal and ultradian dynamics of serum adiponectin in healthy men: comparison with leptin, circulating soluble leptin receptor, and cortisol patterns. J Clin Endocrinol Metab 88, 2838-2843.

Gorostiaga EM, Izquierdo M, Ruesta $\mathrm{M}$, Iribarren $\mathrm{J}$, Gonzalez-Badillo JJ \& Ibanez J (2004) Strength training effects on physical performance and serum hormones in young soccer players. Eur J Appl Physiol 91, 698-707.

Hakkinen K (1989) Neuromuscular and hormonal adaptations during strength and power training. A review. J Sports Med Phys Fitness 29, 9-26.

Hakkinen K, Pakarinen A, Newton RU \& Kraemer WJ (1998) Acute hormone responses to heavy resistance lower and upper extremity exercise in young versus old men. Eur J Appl Physiol Occup Physiol 77, 312-319. 
Houmard JA, Cox JH, MacLean PS \& Barakat HA (2000) Effect of short-term exercise training on leptin and insulin action. Metabolism 49, 858-861.

Kanaley JA, Fenicchia LM, Miller CS, Ploutz-Synder LL, Weinstock RS, Carhart R \& Azevedo JL Jr (2001) Resting leptin responses to acute and chronic resistance training in type 2 diabetic men and women. Int J Obes Relat Metab Disord 25, 1474-1480.

Kim J, Wang Z, Heymsfield SB, Baumgartner RN \& Gallagher D (2002) Total-body skeletal muscle mass: estimation by a new dual-energy X-ray absorptiometry method. Am J Clin Nutr 76, 378-383.

Kraemer WJ, Staron RS, Hagerman FC, et al. (1998) The effects of short-term resistance training on endocrine function in men and women. Eur J Appl Physiol Occup Physiol 78, 69-76.

Laimer M, Ebenbichler CF, Kaser S, Sandhofer A, Weiss H, Nehoda H, Aigner F \& Patsch JR (2002) Weight loss increases soluble leptin receptor levels and the soluble receptor bound fraction of leptin. Obes Res 10, 597-601.

Lammert A, Kiess W, Bottner A, Glasow A \& Kratzsch J (2001) Soluble leptin receptor represents the main leptin binding activity in human blood. Biochem Biophys Res Commun 283, 982-988.

Landt M, Lawson GM, Helgeson JM, Davila-Roman VG, Ladenson JH, Jaffe AS \& Hickner RC (1997) Prolonged exercise decreases serum leptin concentrations. Metabolism 46, 1109-1112.

Landt M, Parvin CA \& Wong M (2000) Leptin in cerebrospinal fluid from children: correlation with plasma leptin, sexual dimorphism, and lack of protein binding. Clin Chem 46, 854-858.

Lea-Currie YR, Wen P \& McIntosh MK (1998) Dehydroepiandrosterone reduces proliferation and differentiation of 3T3-L1 preadipocytes. Biochem Biophys Res Commun 248, 497-504.

Leal-Cerro A, Garcia-Luna PP, Astorga R, Parejo J, Peino R, Dieguez C \& Casanueva FF (1998) Serum leptin levels in male marathon athletes before and after the marathon run. J Clin Endocrinol Metab 83, 2376-2379.

Lemmer JT, Ivey FM, Ryan AS, Martel GF, Hurlbut DE, Metter JE, Fozard JL, Fleg JL \& Hurley BF (2001) Effect of strength training on resting metabolic rate and physical activity: age and gender comparisons. Med Sci Sports Exerc 33, 532-541.

Luukkaa V, Pesonen U, Huhtaniemi I, Lehtonen A, Tilvis R, Tuomilehto J, Koulu M \& Huupponen R (1998) Inverse correlation between serum testosterone and leptin in men. J Clin Endocrinol Metab 83, 3243-3246.

Maamra M, Bidlingmaier M, Postel-Vinay MC, Wu Z, Strasburger CJ \& Ross RJ (2001) Generation of human soluble leptin receptor by proteolytic cleavage of membrane-anchored receptors. Endocrinology 142, 4389-4393.

Mars M, de Graaf C, de Groot CP, van Rossum CT \& Kok FJ (2006) Fasting leptin and appetite responses induced by a 4-day $65 \%$ energy-restricted diet. Int J Obes (Lond) 30, 122-128.

McArdle WD, Katch FI \& Katch VL (1991) Exercise Physiology: Energy, Nutrition and Human Performance, 3rd ed. Philadelphia, PA: Lea \& Febiger.

McCall GE, Byrnes WC, Dickinson A, Pattany PM \& Fleck SJ (1996) Muscle fiber hypertrophy, hyperplasia, and capillary density in college men after resistance training. J Appl Physiol 81, 2004-2012.

Misra M, Miller KK, Almazan C, Ramaswamy K, Aggarwal A, Herzog DB, Neubauer G, Breu J \& Klibanski A (2004) Hormonal and body composition predictors of soluble leptin receptor, leptin, and free leptin index in adolescent girls with anorexia nervosa and controls and relation to insulin sensitivity. J Clin Endocrinol Metab 89, 3486-3495.

Nissen SL \& Sharp RL (2003) Effect of dietary supplements on lean mass and strength gains with resistance exercise: a meta-analysis. J Appl Physiol 94, 651-659.

Pelleymounter MA, Cullen MJ, Baker MB, Hecht R, Winters D, Boone T \& Collins F (1995) Effects of the obese gene product on body weight regulation in ob/ob mice. Science 269, 540-543.
Perusse L, Collier G, Gagnon J, Leon AS, Rae DC, Skinner JS, Wilmore JH, Nadeau A, Zimmet PZ, Bouchard C (1997) Acute and chronic effects of exercise on leptin levels in humans. J Appl Physiol 83, 5-10.

Raastad T, Glomsheller T, Bjoro T \& Hallen J (2001) Changes in human skeletal muscle contractility and hormone status during 2 weeks of heavy strength training. Eur J Appl Physiol 84, 54-63.

Rebuffe-Scrive M, Enk L, Crona N, Lonnroth P, Abrahamsson L, Smith U \& Bjorntorp P (1985) Fat cell metabolism in different regions in women. Effect of menstrual cycle, pregnancy, and lactation. J Clin Invest 75, 1973-1976.

Reinehr T, Kratzsch J, Kiess W \& Andler W (2005) Circulating soluble leptin receptor, leptin, and insulin resistance before and after weight loss in obese children. Int J Obes (Lond) 29, 1230-1235.

Reseland JE, Anderssen SA, Solvoll K, Hjermann I, Urdal P, Holme I \& Drevon CA (2001) Effect of long-term changes in diet and exercise on plasma leptin concentrations. Am J Clin Nutr 73, 240-245.

Ryan AS, Ivey FM, Hurlbut DE, Martel GF, Lemmer JT, Sorkin JD, Metter EJ, Fleg JL \& Hurley BF (2004) Regional bone mineral density after resistive training in young and older men and women. Scand J Med Sci Sports 14, 16-23.

Ryan AS, Pratley RE, Elahi D \& Goldberg AP (2000) Changes in plasma leptin and insulin action with resistive training in postmenopausal women. Int J Obes Relat Metab Disord 24, 27-32.

Sandhofer A, Laimer M, Ebenbichler CF, Kaser S, Paulweber B \& Patsch JR (2003) Soluble leptin receptor and soluble receptor-bound fraction of leptin in the metabolic syndrome. Obes Res 11, 760-768.

Shih R, Wang Z, Heo M, Wang W \& Heymsfield SB (2000) Lower limb skeletal muscle mass: development of dual-energy X-ray absorptiometry prediction model. J Appl Physiol 89, $1380-1386$.

Stein K, Vasquez-Garibay E, Kratzsch J, Romero-Velarde E \& Jahreis G (2006) Influence of nutritional recovery on the leptin axis in severely malnourished children. J Clin Endocrinol Metab 91, 1021-1026.

Tartaglia LA (1997) The leptin receptor. J Biol Chem 272, 6093-6096.

Thong FS, Hudson R, Ross R, Janssen I \& Graham TE (2000) Plasma leptin in moderately obese men: independent effects of weight loss and aerobic exercise. Am J Physiol Endocrinol Metab 279, E307-E313.

van Aggel-Leijssen DP, van Baak MA, Tenenbaum R, Campfield LA \& Saris WH (1999) Regulation of average 24h human plasma leptin level; the influence of exercise and physiological changes in energy balance. Int J Obes Relat Metab Disord 23, 151-158.

van Dielen FM, van 't Veer C, Buurman WA \& Greve JW (2002) Leptin and soluble leptin receptor levels in obese and weightlosing individuals. J Clin Endocrinol Metab 87, 1708-1716.

Wabitsch M, Blum WF, Muche R, Braun M, Hube F, Rascher W, Heinze E, Teller W \& Hauner H (1997) Contribution of androgens to the gender difference in leptin production in obese children and adolescents. J Clin Invest 100, 808-813.

Wade GN \& Gray JM (1978) Cytoplasmic 17 beta-[3H]estradiol binding in rat adipose tissues. Endocrinology 103, 1695-1701.

Yang G, Ge H, Boucher A, Yu X \& Li C (2004) Modulation of direct leptin signaling by soluble leptin receptor. Mol Endocrinol 18, $1354-1362$.

Young NR, Baker HW, Liu G \& Seeman E (1993) Body composition and muscle strength in healthy men receiving testosterone enanthate for contraception. J Clin Endocrinol Metab 77, 1028-1032.

Zaccaria M, Ermolao A, Roi GS, Englaro P, Tegon G \& Varnier M (2002) Leptin reduction after endurance races differing in duration and energy expenditure. Eur J Appl Physiol 87, 108-111.

Zastrow O, Seidel B, Kiess W, Thiery J, Keller E, Bottner A \& Kratzsch J (2003) The soluble leptin receptor is crucial for leptin action: evidence from clinical and experimental data. Int $J$ Obes Relat Metab Disord 27, 1472-1478. 